\title{
Agent-Based Model of the Epidemic Process of Diseases with Multiple Routes of Infection Transmission Development and Evaluation
}

\author{
Chumachenko Dmytro ${ }^{1}$, Chumachenko Tetyana ${ }^{2}$ \\ ${ }^{1}$ Department of Informatics, National Aerospace University "Kharkiv Aviation Institute", \\ Kharkiv, Ukraine \\ ${ }^{2}$ Department of Epidemiology, Kharkiv National Medical University, Kharkiv, Ukraine
}

\begin{abstract}
The paper presents simulation model of the spreading of infectious diseases with multiple routes of infection transmission by the example of Hepatitis B. The structure, states and rules of cooperation of agents as well as the simulation environment are described. The proposed model allows prediction the incidence of infectious diseases in a given time in a particular area based on demographic characteristics, and other social and economic conditions of the population.
\end{abstract}

Keywords: simulation, agent-based model, multiagent model, Hepatitis B, agent, infections with multiple routes of transmission.

\section{INTRODUCTION}

Simulation modeling of infectious disease spread allows identifying the most important routes of disease transmission, risk groups of the population and the main regularities of the epidemic process dynamics and on the basis of the data obtained to make the correct decision in conducting epidemiological surveillance [1]. In the last decade, several models of distribution of hepatitis B have been proposed [2-6]. The most well-known models that are used for these purposes are the model SIR [7], SEIRS [8]. We have developed a simulation model of diseases with multiple routes of infection transmission by example of hepatitis B using data from Kharkiv (Ukraine) [9]. However, the model took into account not all the factors influencing the epidemic process of hepatitis B. In order to eliminate these restrictions an improved model has been developed.

\section{OBJECTIVE}

Is to evaluate the model of diseases with multiple routes of infection transmission by the example of hepatitis B infection spreading

\section{Materials \& Methods}

The nature, complexity and singularities in the behavior of the system make it necessary to use of simulation modeling [10]. A simulation model that is built on the basis of agent-based technology allows considering a lot of factors that affect the epidemic process, to detail agents' properties and to conduct experiments with a sufficiently large populations. Results of a simulation in the presence of an adequate model exposed to statistical analysis to get a response about the effectiveness of any changes in the system. The information technology has been developed to simulate the epidemic process.

We represent the agent as a set of properties:

$\mathrm{a}=\left\langle\mathrm{s}, \mathrm{s}_{\mathrm{t}}, \mathrm{c}, \mathrm{t}_{\mathrm{a}}, \mathrm{l}\right\rangle, \mathrm{a} \in \mathrm{A}, \mathrm{s} \in \mathrm{S}, \mathrm{c} \in \mathrm{C}, \mathrm{t}_{\mathrm{a}} \in \mathrm{T}_{\mathrm{a}}$,

Where $s_{t}$ - time in a state of $s$,

A - set of agents, 
$\mathrm{S}$ - set of different agents states,

C - set of cells of workplace,

$\mathrm{T}_{\mathrm{a}}$ - set of agents types,

1 - life lengths.

Set of states of the agent is determined beforehand and is a regular:

$\mathrm{S}=\{$ Susceptibl e, Exposed, Infected, Convalesce nt, Recovered, Dead $\}$.

- Susceptible - agent is healthy (may be subject to contamination). In this case a healthy meant an agent which is susceptible to the disease epidemic simulated process.

- Exposed - agent underwent disease. This state represents the incubation period. During this time, the agent is not yet sick, but has a chance to transmit the infection.

- Infected - agent is sick. Agents in this state are the most likely source of infection for other agents.

- Convalescent - agent is recovering. This condition is characterized by periods when the symptoms have disappeared clinically, but the agent may still be a carrier of the disease and the source of infection. The presence of such a condition is typical for certain infectious diseases.

- Recovered - agent recovered (acquired immunity). Agents in this state are no longer subject to possible sick.

- Dead - agent dead because of old age or due to disease.

In the simulation such a phenomenon as the epidemic process, it is clear that participants may interact with each other not only in direct physical contact (eg, a disease transmitted by airborne droplets). Processing of such events is rather complicated, which leads to slow down the simulations process. In this paper we propose to simplify the consideration of infection, through the establishment of single cell accessories agents. This allows taking into account the possibility of interaction of agents and thus significantly reducing the loss of productivity.

To increase the granularity of the population in terms of its membership of conditional social groups were identified types of agents, which are presented as follows:

$\mathrm{t}=\left\langle\overline{\mathrm{P}}_{\mathrm{t}}, \bar{\tau}_{\mathrm{t}}\right\rangle$

Where $\overline{\mathrm{P}}_{\mathrm{t}}$ - vector of probabilities that are specific to the type of agent,

$\bar{\tau}_{t}-$ Vector of constants of model time.

The constructed model can be extended due to the increase of dimension vectors. Within this task limited to the following set:

$\overline{\mathrm{P}}_{\mathrm{t}}=\left(\mathrm{P}_{\mathrm{b}}, \mathrm{P}_{\mathrm{hr}}, \mathrm{P}_{\mathrm{hh}}, \mathrm{P}_{\mathrm{sr}}, \mathrm{P}_{\mathrm{sh}}\right)$,

Where $\mathrm{P}_{\mathrm{b}}$ - probability of a birth of specified type agent,

$\mathrm{P}_{\mathrm{hr}}$ - The probability that the agent goes into the risk area in a healthy state,

$\mathrm{P}_{\mathrm{hh}}$ - The probability that the agent will move in a healthy state to the "Hospital",

$\mathrm{P}_{\mathrm{sr}}$ - The probability that the agent in the sick state goes into a risk area,

$\mathrm{P}_{\mathrm{sh}}$ - The probability that the agent in the sick state will go to the "Hospital".

$\bar{\tau}_{\mathrm{t}}=\left(\tau_{\mathrm{h}}, \tau_{\mathrm{r}}, \tau_{\mathrm{m}}\right)$

Where $\tau_{\mathrm{h}}$ - number of model time that this type of agent holds, staying in the "Home", 
$\tau_{\mathrm{r}}$ - Number of model time that this type of agent holds, staying in the area at risk.

$\tau_{m}$ - Number of model time that this type of agent holds, staying in the "Hospital".

\section{RESUlTS \& DISCUSSION}

On the basis of improved modeling techniques a model of hepatitis B has been developed. A Flowchart of the agent transition to a new field is presented in Figure 1.

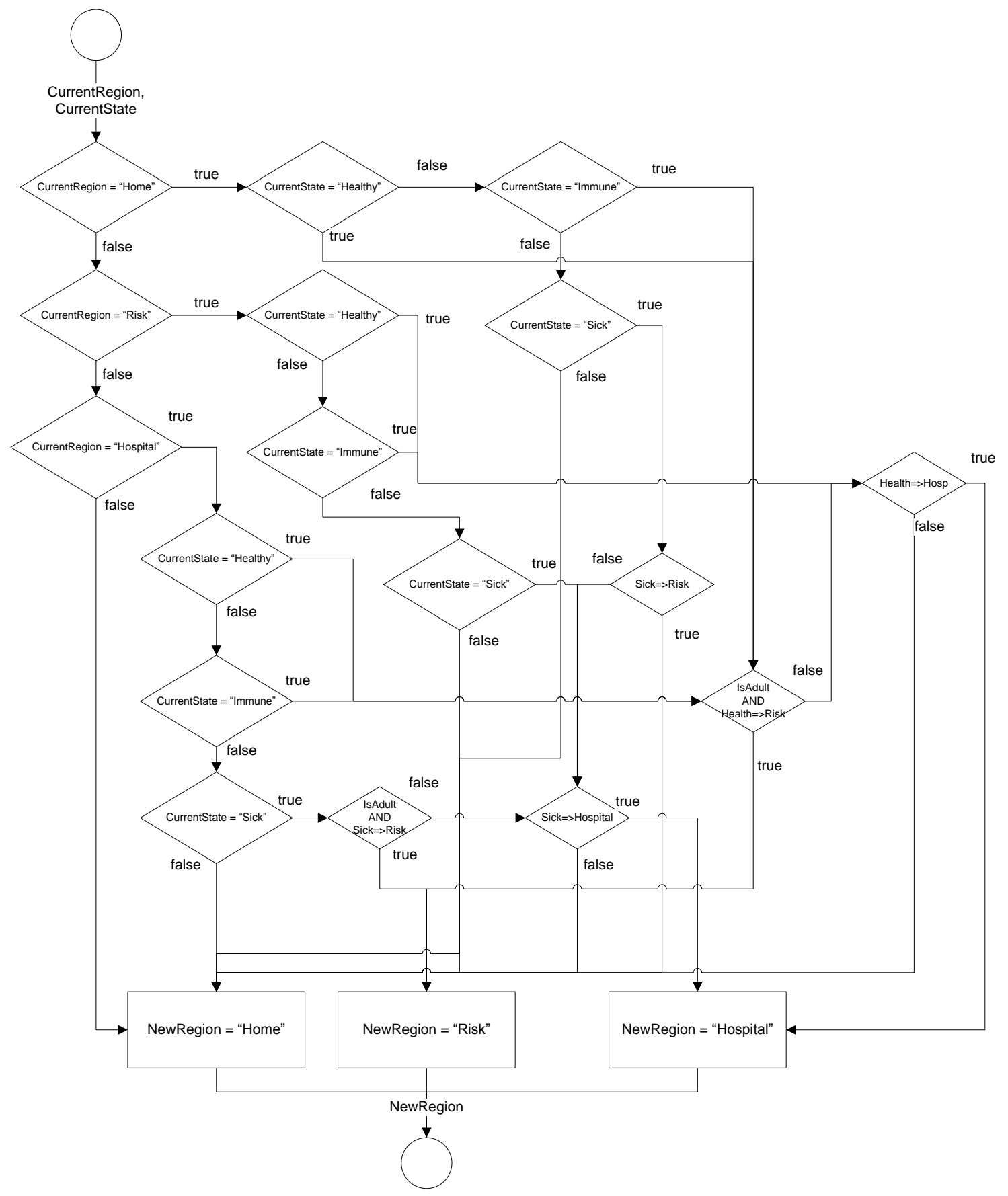

Fig1. A Flowchart of the agent transition to a new field

Screen forms are presented in Figures 2, 3.

Signs of agents, their rules of behavior and interaction, as well as the properties of the environment have been overlooked. The experimental results the model were compared with data of the real incidence and risk groups in Kharkiv from 2003 to 2015. The forecast of the incidence of hepatitis B for 2016-2018 has been made. 


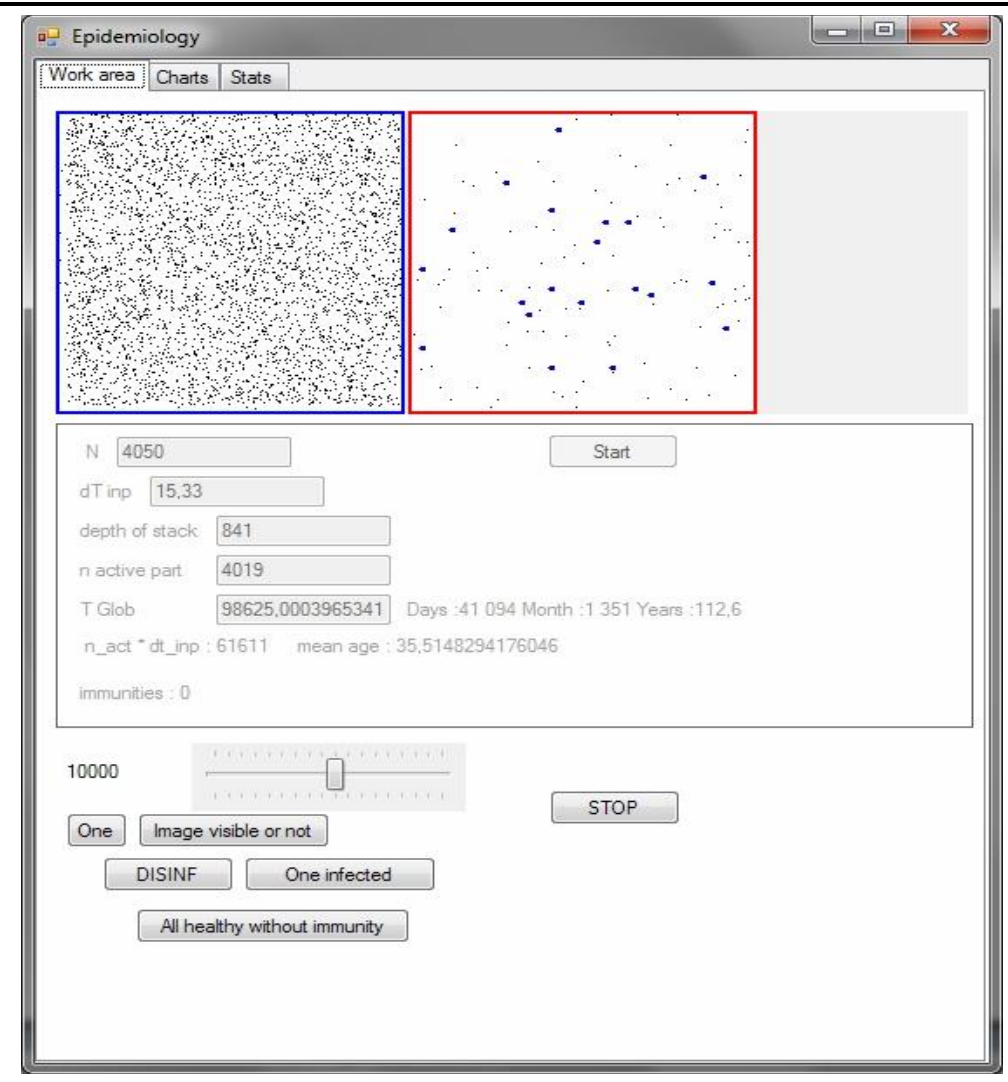

Fig2. The main panel of the simulation process management

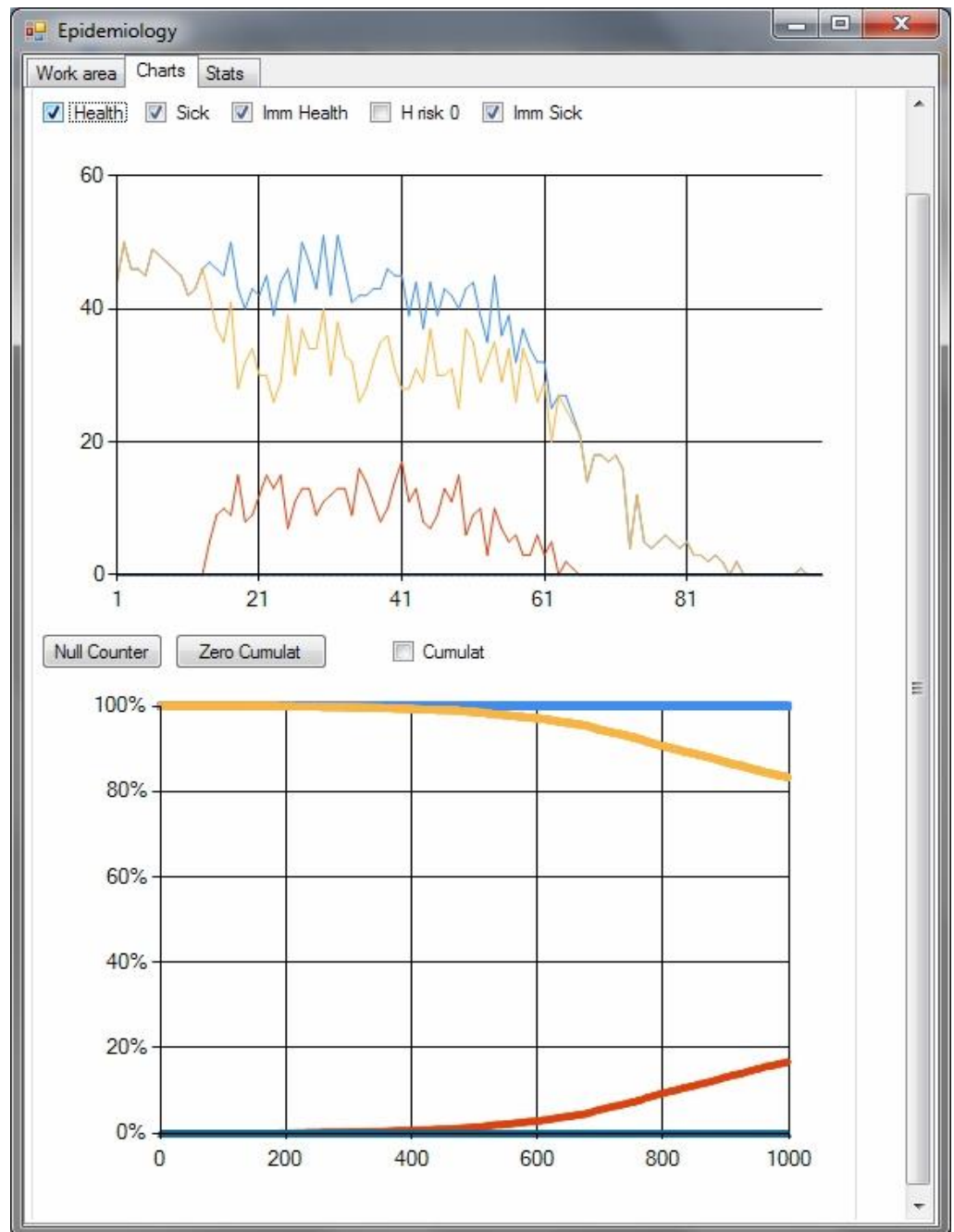

Fig3. Graphical visualization of simulation process 


\section{Conclusions}

As a result of the model improvement, it became more accurate and has improved its productivity. The simulation results allow predicting the incidence of hepatitis B in a given time in a particular area with regard to demographic characteristics and capabilities public health and other social conditions of the population.

\section{REFERENCES}

[1] Ahmed, E., Agiza, H.N., Hassan, S.Z.: On modelling hepatitis B transmission using cellular automata. J. Stat. Phys., 92(3/4), 1998. - pp. 116-120.

[2] Hethcote, H.W. : The mathematics of infectious diseases. Society for Industrie and Applied Mathematics (SIAM review). - 2000; 42. pp. 599-653.

[3] Introduction to Mathematical Modeling. Edited by Trusov P.V. 440 p. M.: Logos (2004) Введение в математическое моделирование. Учебное пособие. Под ред. П. В. Трусова. М.: Логос, 2004. 440 c.

[4] O’Leary, C., Hong, Z., Zhang, F., Dawood, M., Smart, G., Kaita, K., Wu, J. : A mathematical model to study the effect of hepatitis B virus vaccine and antivirus treatment among the Canadian Inuit population. European Journal Clinical Microbiological Diseases, 2010, 29. - pp. 63-72

[5] Shoujun Zhao, Zhiyi Xu, Ying Lu. : Mathematical model of hepatitis B virus transmission and its application for vaccination strategy in China. International Journal of Epidemiology, 2000; 29. pp. 744-752;

[6] Sutton, A.J., Gay, N.G., Edmunds, W.J., Andrews, N.J., Hope, V.D., Gilver, R.L., Piper, M., Gill, O.N. : Modeling the hepatitis B vaccination programme in prisons. Epidemiol. Infec., 2006, 134. pp. 231-242

[7] Sutton, A.J., Gay, N.G., Edmunds, W.J., Hope, V.D., Gill, O.N.: Modeling the force of infection for hepatitis B and C in injection drug users in England and Wales. Hickman - BMC Infectious Diseases 2006, 6:93

[8] D'ebarre F. SIR models of epidemics [Electronic resource] / F. D'ebarre // Level 1 module in "Modelling course in population and evolutionary biology". - Zurich: Institute of Integrative Biology, 2010. - Access mode: http://www.tb.ethz.ch/education/model/SIR/sir.pdf.

[9] Chumachenko T., Chumachenko D., Sokolov O. Multiagent Simulation of the Hepatitis B Epidemic Process // ISDS 2012 Conference "International Society for Disease Surveillance Conference.Expanding Collaborations to Chart a New Course in Public Health Surveillance " / San Diego, USA/ December, 4-5/ Abstracts. - San Diego, 2012. - P.39. Access mode: http://www.syndromic.org/2012-ISDS-Conference-Abstracts.pdf

[10] Zhang Li Juan Global Dynamics of an SEIRS Epidemic Model with Constant Immigration and Immunity [Text] / Li Juan Zhang, Yingqiu Li, Qingqing Ren, Zhenxiang Huo // WSEAS transactions on mathematics. Issue 5, Volume 12. - 2013. - P. 630-640.

\section{AUTHORS' BIOGRAPHY}

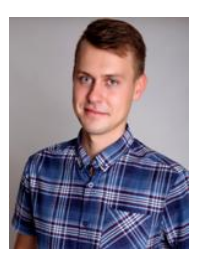

Chumachenko Dmytro, is a Teaching Assistant of Department of Informatics of National Aerospace University "Kharkiv Aviation Institute" (Kharkiv, Ukraine). Area of scientific interests: agent-based simulation, artificial intelligence, fuzzy logic, information security.

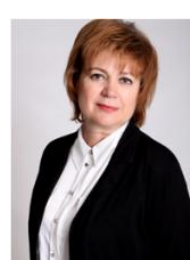

Chumachenko Tetyana, is Doctor of Science, Medical Doctor, Head of Department of Epidemiology of Kharkiv National Medical University. Area of scientific interests: epidemiology, epidemiological surveillance methods using information technology. 